\title{
A Preliminary estimation of baseline urinary hydroxyproline/creatinine levels in a study population of healthy Nigerians
}

\author{
Chidinma Ifechi Onwuka, ${ }^{1}$ Chidozie Onwuka, ${ }^{2}$ Chibuzor Uguru ${ }^{2}$ \\ ${ }^{1}$ Department of Obstetrics and Gynaecology; ${ }^{2}$ Department of Oral and Maxillofacial Surgery, University of \\ Nigeria Teaching Hospital, Enugu
}

\begin{abstract}
Background:Hydroxyproline is one of the biochemical markers that can be measured objectively as an indicator of normal biological processes or pathological processes. It is usually raised in disease conditions that are associated with bone resorption.

Aim: To determine the urinary hydroxyproline/creatinine levels in a study population of healthy Nigerians.

Methods: This study recruited 22 consenting participants who served as control for another study at the University of Nigeria Teaching Hospital (UNTH) Ituku-Ozalla, Enugu. All participants were required to fast for at least 12 hours overnight and their early morning second void urine collected between $7 \mathrm{am}$ and $8 \mathrm{am}$. The collected urine samples were stored frozen at $-20^{\circ} \mathrm{C}$ until analysis. Colorimetric method of analysis of urinary hydroxyproline and creatinine were done using Biovisionhydroxyproline kit and Randoxcreatinine kit respectively.Bivariate analysis was conducted on the collated data using statistical package of social science (SPSS)
\end{abstract}

Correspondence: Chidozie Onwuka, Department of Oral and Maxillofacial Surgery, University of Nigeria Teaching Hospital, Enugu. E-mail: chidozie.onwuka@unn.edu.ng

Keywords: Biomarkers; urinary, hydroxyproline;creatinine.

Conflict of interest: The authors declare no conflict of interest.

Ethics approval: This study was approved by the Ethics committee of the University of Nigeria Teaching Hospital, Ituku-Ozalla, Enugu (Ref:UNTH/CSA/329/Vol.5).

Consent for publication: All participants gave consent for the study and publication.

Availability of data and materials: The datasets used and/or analyzed during the current study are available from the corresponding author on reasonable request

Acknowledgements: Authors wish to thank late Dr Uche Mgbeokwere, other faculty members and Nurses of Oral and Maxillofacial Surgery Department of University Nigeria Teaching Hospital, Enugu for their immense contribution towards this research.

Received for publication: 4 August 2020

Revision received: 24 October 2020.

Accepted for publication: 24 October 2020.

This work is licensed under a Creative Commons Attribution NonCommercial 4.0 License (CC BY-NC 4.0).

${ }^{\circ}$ Copyright: the Author(s),2020

Licensee PAGEPress, Italy

Annals of Clinical and Biomedical Research 2020; 1:98

doi:10.4081/acbr.2020.98 version 19. The results were recorded as urinary hydroxyproline alone $(\mu \mathrm{g} / \mu \mathrm{L})$ and as urinary hydroxyproline/creatinine ratio.

Results: The mean urinary hydroxyproline level of $0.020 \pm 0.013 \mu \mathrm{g} / \mu \mathrm{L}$ and urinary hydroxyproline/ creatinine ratio of $0.016 \pm 0.006$ were noted for healthy Nigerians.

Conclusions: The urinary hydroxyproline levels in the study population of healthy Nigerians are within normal values reported in other healthy populations.

\section{Introduction}

Biochemical markers are useful in management of patients with metabolic bone diseases and monitoring fracture healing. ${ }^{1,2}$ They provide useful clinical evidence of normal and pathological processes that reflect bone cell activity. ${ }^{3}$ Changes in their levels are not disease specific rather they reflect changes in bone metabolism and could serve as an alternative to bone histology. 4,5

Biomarkers measurements are usually associated with variable techniques and application which typically are non-invasive and can be conveniently measured in urine and blood. ${ }^{6}$ Urinary measurements of these markers are non-invasive and can be performed at frequent intervals with less risk as compared to other methods of bone assessment such as plain radiographs, histomorphometry, calcium fluxes, densitometric procedures and computer assisted imaging for bones. ${ }^{7}$ They provide an alternative way of assessing bone cellular activity. ${ }^{8-11}$

Bone cellular activity involves bone resorption and bone formation in which balance is maintained in health. These activities results in excretion of biochemical markers of which hydroxyproline is a marker of bone resorption. Hydroxyproline is a by-product of post translational hydroxylation of proline within the peptide chain that is released by collagen degradation which is not reused but only catabolised and excreted in urine. ${ }^{12-14}$ More than half of human collagen comes from the bone with rate of bone turnover being faster than soft tissue thus making excretion of hydroxyproline in urine a good marker of bone resorption. ${ }^{15}$

Hydroxyproline excreted in urine may be detected either as a free or peptide bound hydroxyproline by colometric or High Performance Liquid Chromatography (HPLC) methods. ${ }^{13,16}$ Its measurement is the most performed measure of bone resorption and has the longest history of use. ${ }^{10,17,18}$ Among its uses include monitoring of bone fracture union, metabolic bone diseases such as osteoporosis and in monitoring cancer spread from soft tissue to bone. ${ }^{2,18,19}$ Scarce resources and poor facilities in Nigeria are necessitating the exploration ofbone biomarkers such as hydroxylproline as an alternative and cheaper way of monitoring bone disorders. However, normal baseline values in healthy individuals have been reported in literature for different clime but little is known of baseline values in Nigerians. This study was therefore aimed at measuring the normal baseline value of urinary huydroxyproline/creatinine in a study population of healthy Nigerians. 


\section{Materials and Methods}

\section{Study design}

This was a hospital based prospective cross sectional analytical study using consecutive subjects that met the inclusion criteria and served as control for another study.

\section{Study location}

Study was conducted at the Oral and Maxillofacial Surgery Department of the University of Nigeria Teaching Hospital (UNTH)Ituku- Ozalla, Enugu. UNTH is one of the tertiary hospitals in the South-Eastern Nigeria with patients from different tribes and religion in Enugu state and neighbouring states such as Anambra, Abia, Ebonyi and Benue.

\section{Inclusion and exclusion criteria}

Consenting participants between the ages of 18years and 40years were recruited. Patients presented with bone destructive lesions (inflammatory or metabolic) or had fractures of any bone within the last year, as well as other conditions such lactating mothers and postmenopausal women. Patients below 18years and above 40 years of age or those on steroid therapy/oral contraceptives were excluded.

\section{Participants}

Twenty-two healthy participants who served as control for another study were used. They were comprehensively assessed, bio-data and medical history were taken and physical examination was done for each patient after signing the informed consent form and the data was entered into a proforma designed for the study.

\section{Urine collection}

Participants were required to fast overnight for at least 12 hours before sample collection. Early morning second urine voided between $7 \mathrm{am}$ and $8 \mathrm{am}$ were collected in a plastic urine bottle without preservative from the participants by the researchers. This provides a reliable data on bone degradation. ${ }^{20}$ The samples were well labelled and stored frozen in the laboratory in a freezer with thermometer maintained at $-20^{\circ} \mathrm{C}$ till analysis

\section{Analysis}

The collected stored urine samples were thawed and analyzed for urinary hydroxylproline and urinary creatinine. Hydroxyproline research kit manufactured by Biovision Inc. (Milpitas, CA, USA) was used in the colorimetric analysis of urinary hydroxyproline. They were incubated at room temperature for five minutes. Hundred microliters $(\mu \mathrm{L})$ of DMAB reagent was then added to each, and the sample were incubated for 90 minutes at $60^{\circ} \mathrm{C}$. The plates were read on a micro plate reader at $560 \mathrm{~nm}$. The reading from the standard solution was used to generate linear graph from which sample readings were gotten. The thawed urine samples were also analyzed for urinary creatinine using modified Jaffe's method as suggested by Bowers ${ }^{21}$ with creatinine research kit manufactured by Randox Laboratories Limited(Crumlin, County Antrim,United Kingdom). The creatinine of each sample was calculated using the formula: A2- A1 / Std $2-$ Std $1 \times$ Std concentration $\times 50$.

\section{Statistical analysis}

Data collated was analyzed using Statistical Package for Social Sciences (SPSS) version 19. Bivariate analysis was done, continuous variable were summarized using means and standard deviations while categorical variables were summarized using frequency and percentages. Means of continuous variables were compared using student's t test and ANOVA. All tests were significant at probability level $\mathrm{p}<0.05$.

\section{Results}

Twenty-two urine samples were analyzed for urinary hydrox-

Table 1. Mean urinary hydroxyproline of the subjects.

\begin{tabular}{lc} 
& Mean \pm SD \\
Hydroxyproline (ug/uL) & $0.020 \pm 0.013$ \\
Creatinine (ug/uL) & $1.25 \pm 0.68$ \\
\hline Hydroxyproline/creatinine & $0.016 \pm 0.006$ \\
\hline
\end{tabular}

Table 2. Mean urinary hydroxyproline comparison between male and female of the subjects.

\begin{tabular}{lcccc} 
& Male mean \pm SD & Female mean \pm SD & \\
Hydroxyproline $(\mu \mathrm{g} / \mu \mathrm{L})$ & $0.019 \pm 0.012$ & $0.025 \pm 0.017$ & 0.990 \\
Hydroxyproline/creatinine ratio & $0.016 \pm 0.006$ & $0.017 \pm 0.003$ & 0.334 \\
\hline
\end{tabular}

Table 3. Mean urinary hydroxyproline comparison across the age groups of the male and female subjects.

\begin{tabular}{|c|c|c|c|c|c|c|c|}
\hline & $\begin{array}{c}20-24 \\
\text { Mean } \pm \text { SD }\end{array}$ & $\begin{array}{c}25-29 \\
\text { Mean } \pm \text { SD }\end{array}$ & $\begin{array}{c}\text { Age (years) } \\
30-34 \\
\text { Mean } \pm \text { SD }\end{array}$ & $\begin{array}{c}35-39 \\
\text { Mean } \pm \text { SD }\end{array}$ & $\begin{array}{c}>39 \\
\text { Mean } \pm \text { SD }\end{array}$ & $F$ & $P$ value \\
\hline Male & & & & & & & \\
\hline $\begin{array}{l}\text { Hydroxyproline (ug/uL) } \\
\text { Hydroxyproline/creatinine }\end{array}$ & $\begin{array}{l}0.01 \pm 0.01 \\
0.02 \pm 0.01\end{array}$ & $\begin{array}{l}0.02 \pm 0.02 \\
0.01 \pm 0.01\end{array}$ & $\begin{array}{l}0.01 \pm 0.01 \\
0.01 \pm 0.01\end{array}$ & $\begin{array}{l}0.02 \pm 0.01 \\
0.02 \pm 0.03\end{array}$ & $\begin{array}{l}0.02 \pm 0.01 \\
0.02 \pm 0.01\end{array}$ & $\begin{array}{l}0.946 \\
0.613\end{array}$ & $\begin{array}{l}0.474 \\
0.662\end{array}$ \\
\hline $\begin{array}{l}\text { Female } \\
\text { Hydroxyproline (ug/uL) } \\
\text { Hydroxyproline/Creatinine }\end{array}$ & $\begin{array}{l}0.02 \pm 0.02 \\
0.02 \pm 0.01\end{array}$ & $\begin{array}{l}0.03 \pm 0.02 \\
0.02 \pm 0.01\end{array}$ & - & $\begin{array}{l}0.02 \\
0.02\end{array}$ & - & $\begin{array}{l}0.048 \\
0.986\end{array}$ & $\begin{array}{l}0.954 \\
0.469\end{array}$ \\
\hline
\end{tabular}


yproline levels and urinary creatinine levels. The results were recorded as urinary hydroxyproline levels alone and urinary hydroxyproline/creatinine ratio. The gender distribution of the subjects was 15 males accounting for $68.2 \%$ of the subjects and 7 females accounting for $31.8 \%$ of the subjects. The mean ages of subjects were $28.45 \pm 6.8$ years. Age group of 20-24 years of age accounted for $50.0 \%$ of the participants, while the age group of 25 29 and $30-34$ years of age accounted for $4.5 \%$ and $13.6 \%$ respectively. Subjects within age group of 35-39 years and $>39$ years accounted for $13.7 \%$ and $18.2 \%$ respectively. Nineteen participants had tertiary education with only 3 participants having secondary education.

A mean value of $0.020 \pm 0.013 \mu \mathrm{g} / \mu \mathrm{L}$ for urinary hydroxyproline and $0.016 \pm 0.006$ for urinary hydroxyproline/creatinine ratio was noted in the study (Table 1).

The mean urinary hydroxyproline levels for males and females in the study were $0.019 \pm 0.012 \mu \mathrm{g} / \mu \mathrm{L}$ and $0.025 \pm 0.017 \mu \mathrm{g} / \mu \mathrm{L}$ respectively whereas the mean urinary hydroxyproline/creatinine ratio value was $0.016 \pm 0.006$ for males and $0.017 \pm 0.003$ for females. There were no significant differences between males and females in the study $(\mathrm{p}=0.334)$ for urinary hydroxyproline levels and for urinary hydroxyproline/creatinine ratio, $p=0.604$ (Table 2).

No significant difference was found between the age groups in mean values of urinary hydroxyproline and urinary hydroxyproline/creatinine ratio values (Table 3 ).

\section{Discussion}

The increased incidence of metabolic and mestastic bone diseases have necessitated renewed interest in bone metabolism biomarkers in recent times. Despite their usefulness in management of bone disease ${ }^{1,17}$ there are paucity of data in Nigeria especially among Igbos on the baseline values of some of these biomarkers thus necessitating this preliminary study. We noted a mean urinary hydroxyproline/creatinine ratio level of $0.016 \pm$ 0.006 among healthy Nigerians in this study. This mean urinary hydroxyproline/creatinine value was very close to the range reported by Hodgkinson and Thompson, who noted that the normal value for fasting urinary hydroxyproline/creatinine ratio for men and premenopausal women was $0.003-0.015$ in their study of 144 healthy hospital workers, aged between 18-59years, in Leeds, United Kingdom. ${ }^{22}$ Furthermore, the mean urinary hydroxyproline/creatinine ratio was noted to be $0.016 \pm 0.006$ for males and $0.017 \pm 0.003$ for females. This value obtained in our study was close to values reported by George, ${ }^{23}$ who noted a value of 0.013 \pm 0.007 for males and $0.012 \pm 0.007$ for females in his study of urinary and anthropometric indices of bone density in healthy Nigerian adults. Similarly, a urinary hydroxyproline/creatinine ratio of $0.010 \pm 0.04$ among 52 healthy cancer free Indian males aged between 20-80years was noted by Sarvariet al., ${ }^{18}$ The slight difference in values of urinary hydroxyproline/creatinine ratio noted in this study and the values reported in studies of Sarvariet al., Hodgkinson and Thompson and George, may be due to analytical variability which has to do with method of analysis. ${ }^{18,22,23}$ Acid hydrolysis was used in this study while Hodgkinson and Thompson used resin-catalysed hydrolysis even though they noted no significant difference between results obtained by acid hydrolysis and those obtained by resin-catalysed hydrolysis. ${ }^{22}$ Sarvariet $a l$., employed modified Neuman and Logan method of hydroxyproline determination which does not involve acid hydrolysis. ${ }^{18}$ Racial differences may have also accounted for the difference in values between our study and those from Britain
andIndia. There was no significant gender difference in urinary hydroxyproline/creatinine ratio noted in this study which is similar to reports in the literature. ${ }^{20,22-24}$ There was also no significant difference in urinary hydroxyproline/creatinine ratio across the male age groups of in this study. This finding is similar to George's report of no significant increase in urinary hydroxyproline/creatinine ratio among healthy adult Nigerian males. ${ }^{23} \mathrm{He}$ attributed this to the fact that there is no significant age related bone loss in males as compared to females.Similarly, Sarvariet al. also noted no significant difference in the urinary hydroxyproline/creatinine ratio among healthy Indians aged 20-80 years and they attributed this to insignificant age related bone loss in males. ${ }^{18}$ In females, this study observed no significant difference among the age groups; this may be due to the fact that the females in this study were premenopausal. Many studies noted an increase in urinary hydroxyproline/creatinine ratio among females as they age from premenopausal to peri and postmenopausal age. ${ }^{17,23,25}$ They attributed this increase in urinary hydroxyproline/creatinine ratio to bone loss associated with menopause. This study however, observed a higher value in mean urinary hydroxyproline/creatinine ratio in females as compared to males and this is in contrast to George findings, which noted a higher value in males as compared to females. ${ }^{23}$ In conclusion, the urinary hydroxyproline levels in the study population of healthy Nigerians are within the normal values reported in other healthy populations. Therefore, $0.016 \pm 0.006$ for males and $0.017 \pm 0.003$ for females may serve as a baseline for urinary hydroxyproline/creatinine ratio in healthy young Nigerian adults.

\section{Limitations}

The small sample size of the study may have reduced the power of the study. Pre analytical and analytical variability associated with bone metabolism markers measurement such as circadian rhythm and sample processing may also have affected our study. However, further study with larger sample size is recommended.

\section{References}

1. Heer M, Baecker N, Milka C, et al. Immobilization induces a very rapid increase in osteoclast activity. Acta Astronaut 2005;57:31-5.

2. Mukhopadhyay M,Sinha R, Pal M, et al. Role of common biochemical markers for the assessment of fracture union. Ind $\mathrm{J}$ ClinBiochem26:274-8.

3. Briot K, Roux C. Biochemical markers of bone remodelling. GynecolObstert fertile 2005;33:1009-13.

4. Seibel MJ. Biochemical markers of bone turnover, part 1: biochemistry and variability. Clinical Biochem Rev 2005;26:97122.

5. Singer FR, Eyre DR. Using biochemical markers of bone turnover in clinical practice. Cleve Clin J Med 2008;75:73950 .

6. Watts NB.Clinical utility of biochemical markers of bone remodelling. ClinChem 1999;45:1359-68.

7. Deftos LJ. Bone protein and peptide assays in the diagnosis and management of skeletal disease. ClinChem 1991;37:11438.

8. Delmas PD. Biochemical markers of bone turnover J Bone Miner Res 1993;2:S549-55.

9. Carvo MS, Eyre DR, Gunderg CM. Molecular basis and clinical applications of biological marker of bone turnover. 
